\title{
Difference in Body Mass Index between Socio-economically Deprived and Non-Deprived Mothers in the First Trimester of Pregnancy
}

\author{
E. M. Barrett ${ }^{1}$, M. Lane ${ }^{1}$, A. O’Higgins ${ }^{2}$, L. Mullaney ${ }^{1}$, M. J. Turner ${ }^{2}$ and D. McCartney ${ }^{1}$ \\ ${ }^{1}$ Dublin Institute of Technology, Kevin Street, Dublin 8, Republic of Ireland and ${ }^{2}$ UCD Centre for Human Reproduction, \\ Coombe Women and Infants' University Hospital, Cork St., Dublin 8, Republic of Ireland
}

Obesity occurs at high frequency among Irish obstetric populations ${ }^{(1)}$. As obesity increases the risk of adverse outcomes for both mother and infant, this is a major concern ${ }^{(2)}$. This study investigated the relationship between markers of material and social deprivation and maternal body mass index (BMI) status in the first trimester of pregnancy. One hundred and sixteen women aged 16-41years (mean age $=29.5$ years $)$ were recruited at their booking visit (9-16 weeks gestation) to a large Dublin maternity hospital. The sample included both public and semi-private patients. Bodyweight was measured using a TANITA MC-180 body composition analyzer (Pharmed Ltd., Mount Auburn, Millmount Road, Mullingar, Co. Westmeath, Ireland). Height was recorded by nursing staff with a SECA digital height measure (Seca Ltd., 40 Barn St., Birmingham B5 5QB, UK.) using standardised procedures ${ }^{(3)}$.

The socioeconomic status of the participants was assessed by means of formal education and material deprivation status. Participants were classified into four educational categories: no formal or primary education, lower secondary education, upper secondary education and third level education. Material deprivation status was assessed by determining the number of basic necessities ${ }^{(4)}$ which respondents had had to forego in the previous year due to lack of money, with participants categorized into two groupings - non-deprived (0 indicators) and deprived ( $\geqslant 1$ indicator).

Forty seven percent of participants $(n=54)$ were of ideal BMI $\left(20-24.9 \mathrm{~kg} / \mathrm{m}^{2}\right)$, while $27.6 \%$ of the sample $(n=32)$ fell into the overweight category $\left(25-29.9 \mathrm{~kg} / \mathrm{m}^{2}\right)$ and $16.4 \%(n=19)$ were classified as obese $\left(\mathrm{BMI} \geqslant 30 \mathrm{~kg} / \mathrm{m}^{2}\right)$. Independent samples $t$-test was used to compare BMI between women who were materially deprived and those who were not. BMI was greater in those who were deprived $\left(27.0 \mathrm{~kg} / \mathrm{m}^{2}\right)$ than those who were non-deprived $\left(24.6 \mathrm{~kg} / \mathrm{m}^{2}\right)(p=0.008)$.

One-way analysis of variance (ANOVA) was used to compare BMI with educational status. There was no difference in BMI according to educational status $(p=0.256)$.

These findings suggest that markers of material disadvantage such as deprivation may be more important predictors of overweight and obesity in than sociological markers such as educational status among pregnant women in Ireland.

1. Dennedy MC, Avalos G, O’Reilly MW et al. (2010) Diabetes 2010 July; (Suppl): 1952.

2. Guelinckx, I., Devlieger, R., Beckers, K. et al. (2008) Obesity Reviews, 9: 140-150.

3. McCarthy SN, Harrington KE, Kiely M et al. (2001) Public Health Nutrition: 4(5A), 1099-1106.

4. Government of Ireland (2007) National Action Plan for Social Inclusion 2007-2016. Dublin: The Stationery Office. (www.socialinclusion.ie/documents/ NAPinclusionReportPDF.pdf - accessed 10th March 2013.) 